\section{Clinica Ciruirgiea}

\section{COMO DIMINUIR 0 ÍlEO PÓS-OPERATÓRIO?}

A atividade intestinal pode ficar prejudicada após cirurgias abdominais e extra-abdominais. A atividade do intestino delgado retorna ao normal em algumas horas, o estômago em 24 a 48 horas e o cólon em 3 a 5 dias. Essa atividade intestinal diminuída também é conhecida como íleo adinamico ou íleo paralítico. $\bigcirc$ íleo adinamico é diretamente proporcional ao trauma abdominal, isto é, quanto maior é o trauma ou a manipulação intestinal maior é o íleo. A anestesia geral com opiáceos ou anestesia peridural com morfina são causadores de íleo adinamico. A peridural com bupivacaina diminui o íleo e a analgesia pós-operatória com opiáceos prolonga o íleo paralítico.

A deambulação precoce pós-operatória parece diminuir o período de íleo, além de prevenir a atelectasia, a pneumonia e a trombose venosa profunda. A inserção de sonda nasogástrica no pós-cirúrgico previne os vômitos, a náusea e os perigos da aspiração traqueal de secreções gástricas no pós- operatório com íleo adinâmico.

O uso de metoclopramida no pós-operatório diminui o período de íleo, além de permitir a retirada mais precoce da sonda naso-gástrica. A cisaprida endovenosa também mostrou diminuição do período de íleo paralítico.

Deve-se evitar o uso de opiáceos na analgesia pós-operatória em favor do uso de antinflamatórios não-hormonais. A reposição hidroeletrolítica adequada no pós-operatório mostrou abreviação do íleo principalmente com soluções contendo sódio e potássio.

Em futuro próximo estarão disponíveis drogas opiáceas que propiciarão boa analgesia sem efeitos colaterais intestinais além de drogas específicas para aumentar a motilidade intestinal nos casos de íleo prolongado.

Conclusão: o íleo adinamico ainda é um problema no pós-operatório de cirurgias abdominais, com etiologia multifatorial e deve ser tratado com diferentes abordagens de acordo com cada caso.

\section{ELIAS JiRJoss ILIAS}

Referências

1) Luckey, A;Livingston, E;Tache, Y. Mechanisms and Treatment of Postoperative lleus. Arch Surg. 2003; 138:206-2 14.

2) Baig, MK; Wexner, SD. Postoperative lleus: A Review. Dis Colon Rectum 2004; 47: 516-526.

\section{Medieina Farmacêutica}

\section{Como assegurar benefício aOS pacientes após SUA PARTICIPAÇÃO EM PESQUISAS CLÍNICAS?}

O desejo de colaborar com o desenvolvimento da ciência muitas vezes move os indivíduos a se engajarem em pesquisas clínicas, embora raramente o façam por esse motivo exclusi- vamente. Geralmente, há associação de algum outro motivo que o impulsiona nesta direção e o acesso gratuito à medicação, por exemplo, pode ser um destes motivos; entretanto, o quanto ele de fato interfere nesta decisão não é, ainda, muito claro. O fornecimento da medicação durante o estudo é a regra, mas a sua continuidade após a conclusão da pesquisa clínica tem gerado importantes controvérsias. Até recentemente, o foco da discussão em pesquisa clínica vinha sendo a proteção aos direitos e bem-estar dos pacientes, o que seria assegurado através de um desenho apropriado do estudo, minimização dos riscos, revisão por um comitê independente e consentimento do paciente. Os códigos de ética e as legislações mantinham-se silenciosos quanto ao que aconteceria ao final do estudo'.

A Declaração de Helsinque, no parágrafo 30, menciona, por exemplo, que "ao final do estudo, todos os participantes devem ter assegurado o acesso aos melhores métodos comprovados profiláticos, diagnósticos e terapêuticos identificados pelo estudo"2. A posição do ClOMS (Council for International Ethical Guidelines) é de que o produto deve estar "razoavelmente disponível" para o país ou os habitantes da comunidade que hospedou o estudo, após sua conclusão. Exceções deveriam ser justificadas e acordadas por todos os envolvidos antes do início da pesquisa ${ }^{3}$.

Entretanto, ao tentar aplicar esses princípios, algumas questões emergem: quem seria responsável pelo acesso, quanto tempo deve durar este acesso pós-estudo, como seguir os pacientes fora de um contexto de estudo clínico, como assegurar que os potenciais eventos adversos serão adequadamente relatados, caso o medicamento/procedimento ainda não esteja disponível no mercado? Estas e outras questões não são, infelizmente, facilmente respondidas. Além disso, a própria definição do que é "razoavelmente disponível" (ClOMS) ou mesmo "os melhores métodos comprovados" (Declaração de Helsinque) não é muito simples. Com relação à primeira, "razoavelmente disponível" pode ser totalmente gratuito, subsidiado, disponível a preços de mercado ou disponível na rede pública. Já quanto ao termo utilizado na Declaração de Helsinque, dificilmente um único estudo prova definitivamente a eficiência de determinada intervenção.

A Conferência de Aspectos Éticos da Pesquisa em países em desenvolvimento (EARD), de 200 I, já havia discutido o tema da "disponibilidade razoável", conforme consta do documento CIOMS. Este sugere que somente um tipo de benefício poderia justificar a participação dos pacientes em protocolos de pesquisa, quando existem várias outras opções de benefícios para a comunidade como, por exemplo: treinamento em cuidados de saúde, do pessoal da pesquisa, construção de dependências para cuidados de saúde e outras infra-estruturas relacionadas, provisão de medidas de saúde pública, fornecimento do tratamento "standard" disponível, etc. ${ }^{4}$. São todas alternativas que levam em consideração os vários modos que a comunidade pode se beneficiar com a pesquisa. 